\title{
Impact of sulfidation on the bioavailability and toxicity of silver nanoparticles to Caenorhabditis elegans
}

\author{
Daniel L. Starnes ${ }^{1}$, Jason M. Unrine ${ }^{1,2}$, Catherine P. Starnes ${ }^{3}$, Blanche E. Collin ${ }^{1,2}$, Emily \\ K. Oostveen ${ }^{1}$, Rui Ma ${ }^{2,4}$, Gregory V. Lowry ${ }^{2,4}$, Paul M. Bertsch ${ }^{1,2,5}$, and Olga V. \\ Tsyusko ${ }^{1,2, *}$
}

1. Department of Plant and Soil Sciences, University of Kentucky, 1100 South Limestone Street, Lexington, Kentucky 40546, United States

2. Center for Environmental Implications of NanoTechnology (CEINT), P.O. Box 90287, Duke University, Durham, North Carolina 27708-0287, United States

3. Biostatics, Epidemiology, and Research Design; Center for Clinical and Translational Science ,University of Kentucky, Lexington KY 40536, USA

4. Department of Civil \& Environmental Engineering, Carnegie Mellon University, Pittsburgh, Pennsylvania 15213, United States

5. Division of Land and Water, CSIRO, Ecosciences Precinct, Brisbane, QLD Australia

*Corresponding Author: e-mail: olga.tsyusko@uky.edu, phone: 859-257-1777 


\section{Abstract}

2 Sulfidation is a major transformation product for manufactured silver nanoparticles (Ag-MNPs)

3 in the wastewater treatment process. We studied the dissolution, uptake, and toxicity of Ag-

4 MNP and sulfidized Ag-MNPs (sAg-MNPs) to a model soil organism, Caenorhabditis elegans.

5 Our results show that reproduction was the most sensitive endpoint tested for both Ag-MNPs and

6 sAg-MNPs. We also demonstrate that sulfidation not only decreases solubility of Ag-MNP, but

7 also reduces the bioavailability of intact sAg-MNP. The relative contribution of released $\mathrm{Ag}^{+}$

8 compared to intact particles to toxicity was concentration dependent. At lower total Ag

9 concentration, a greater proportion of the toxicity could be explained by dissolved Ag, whereas

10 at higher total $\mathrm{Ag}$ concentration, the toxicity appeared to be dominated by particle specific

11 effects.

12 Keywords: soil, transformation, wastewater treatment, nanotechnology, bioaccumulation 13

14 Capsule:

15 Sulfidation of silver nanoparticles decreases their dissolution and the associated bioavailability 16 and toxicity to Caenorhabditis elegans. 


\section{Introduction}

It is estimated that over 20 tons of silver nanoparticles (Ag-MNPs) are produced annually in the United States (US), with over 300 tons estimated globally, making Ag-MNPs the third most important class of MNPs based on production volume (Gottschalk et al., 2010; Hendren et al., 2011). Ag-MNPs are extensively utilized for their anti-microbial properties in textiles, plastics, and in a variety of health care products (Chen and Schluesener, 2008). During manufacture, use, and product disposal, Ag-MNPs can be released to wastewater streams (Benn and Westerhoff, 2008), where they have been shown to partition largely to sewage sludge during the wastewater treatment process (Kaegi et al., 2011; Schlich et al., 2013b). Nearly 75\% of US households are serviced by wastewater treatment plants (WWTPs) and over half of the biosolids generated are land applied as agricultural fertilizer (EPA 1995). Therefore, land application of biosolids is the primary route of Ag-MNP introduction to terrestrial ecosystems (Blaser et al., 2008; Hendren et al., 2013; Whitley et al., 2013). As MNPs enter WWTPs, they are subjected to biogeochemical transformations, collectively referred to as aging. The biogeochemically driven aging processes include MNP interactions with a range of organic and inorganic ligands along a steep redox and often pH gradient, (Levard et al., 2012; Reidy et al., 2013; Wiesner et al., 2009). For Ag-MNPs, the most important transformation is the sulfidation of zerovalent Ag-MNPs to mixed $\mathrm{Ag}(0)-\mathrm{Ag}$-S phases or $\mathrm{Ag}_{2} \mathrm{~S}$ as indicated by several bench and pilot scale WWTP experiments (Kaegi et al., 2011; Levard et al., 2012; Levard et al., 2011; Whitley et al., 2013).

37 Such transformations of Ag-MNPs can alter their solubility, bioavailability, and toxicity (Kaegi 38 et al., 2013; Levard et al., 2013a; Lombi et al., 2013; Ma et al., 2014). Toxicity of pristine AgMNPs has been shown to be driven by both ion- or particle-specific effects (Levard et al., 2012). 
41 (Xiu et al., 2012; Yang et al., 2012). While other have reported Ag-MNP can cause toxic effects

42 greater than their equivalent ionic (metal salt) concentrations (Choi and $\mathrm{Hu}, 2008$; Meyer et al.,

43

44

45

46

47 2010; Yin et al., 2011). The sulfidation of Ag-MNPs has been shown to reduce the effects of AgMNPs attributable to Ag ion release due to their reduced solubility. (Levard et al., 2013a; Levard et al., 2011; Reinsch et al., 2012; Whitley et al., 2013)

Several studies have previously demonstrated that exposure to Ag-MNPs can elicit a range of toxic responses in a variety of organisms including algae, bacteria, and eukaryotic organisms in both aquatic and terrestrial systems (Fabrega et al., 2009; Gorth et al., 2011; Miao et al., 2009; Roh et al., 2009). Impacts of Ag-MNPs on terrestrial organisms, such as earthworms (Eisenia fetida, E. andrei), have been investigated and include avoidance behavior, decreased reproduction, and changes in expression of several stress response genes linked to oxidative stress (Schlich et al., 2013a; Shoults-Wilson et al., 2011a; Shoults-Wilson et al., 2011b; Tsyusko et al., 2012a).

An emerging tool for assessing the toxicity of MNPs is the use of the model organism, a nematode, Caenorhabditis elegans, which is frequently found in decaying plant material associated with soil(Ellegaard-Jensen et al., 2012; Kim et al., 2012; Meyer et al., 2010; Roh et al., 2010; Roh et al., 2009; Tsyusko et al., 2012b; Williams and Dusenbery, 1990; Zhang et al., 2011a). The popularity of C. elegans as a test species to evaluate MNP toxicity is driven by its invariable cell fate map, fully mapped genome, the availability of mutants, short generation time, and low maintenance cost (Choi et al., 2014; Handy et al., 2012; Kim et al., 2012; Leung et al., 2008; Ma et al., 2009; Meyer et al., 2010; Roh et al., 2010; Roh et al., 2009; Williams and Dusenbery, 1990; Zhang et al., 2011a). In addition, C. elegans can survive and reproduce in a range of media, including those with low ionic strength, which is a more environmentally 
64 representative medium for toxicity testing with Ag-MNPs than e.g. physiological buffer (Choi et 65 al., 2014).

To date, the majority of nanotoxicity studies generally and those utilizing C. elegans

67 specifically, have focused on the effects of pristine Ag-MNPs without taking into account the

68 effects of particle aging (Collin et al., 2014). Pristine Ag-MNPs have previously been shown to

69 cause increased mortality, decreased growth, and decreased reproduction, as well as increased

70 oxidative stress in C. elegans (Kim et al., 2012; Lim et al., 2012; Meyer et al., 2010; Yang et al.,

71 2012). Levard et al. demonstrated decreases in mortality and impacts to growth of the

72 nematodes exposed to sulfidized Ag-MNP (sAg-MNPs) when compared to pristine Ag-MNPs at

73 a S to Ag ratio as low as 0.019 (Levard et al., 2013a). To our knowledge there are no published

74 studies that demonstrated impacts of sulfidation of Ag-MNPs using other sensitive endpoints in

75 C. elegans, such as reproduction or that attempt to quantify differences in Ag bioavailability

76 between Ag-MNPs and sAg-MNPs.

77 The objectives of this study are to investigate and compare the bioavailability and

78 toxicity of Ag-MNPs and sAg-MNPs to C. elegans. Additionally, our aim is to determine if the

79 observed toxicity of Ag-MNPs and sAg-MNPs are exclusively related to the dissolved ion or

80 also include particle-specific effects. We hypothesize that sAg-MNPs will have decreased

81 toxicity and bioavailability compared to pristine Ag-MNPs. We also hypothesize that the ion

82 specific effects of both sulfidized and pristine Ag-MNPs will decrease with increasing exposure

83 concentration based on the limited solubility of these materials, i.e. as the particle to ion ratio

84 increases. 


\section{Materials and Methods}

\section{Silver Nanoparticle Synthesis and Characterization}

Polyvinylpyrrolidone (PVP) coated (pristine) Ag-MNPs were synthesized as previously described (Cheng et al., 2011). These particles were then sulfidated (to produce sAg-MNPs) similarly to Levard et al. (2011) using molar ration of sulfide as 2:1 S/Ag. More detailed descriptions for sAg-MNPs preparation and particle characterization is provided in SI.

\section{Exposure Medium}

The choice of medium can strongly influence the toxicity of Ag-MNPs; therefore, we chose MHRW $(I=0.00395)$ which is a common toxicity testing medium. This medium is low in chloride $(0.11 \mathrm{mmol})$ minimizing precipitation of insoluble $\mathrm{AgCl}$ (Tyne et al., 2013; Yang et al., 2012). We used MINTEQ to calculate equilibrium Ag speciation for our exposure solutions in MHRW, and the saturation indices are negative $(-2.48,-2.17$, and -0.68 for 1,10 , and $100 \mathrm{ppb}$ $\mathrm{Ag}$, respectively) indicating that $\mathrm{AgCl}(\mathrm{s})$ does not precipitate. However, the calculations predict that about $8 \%$ of the $\mathrm{Ag}$ is present as $\mathrm{AgCl}(\mathrm{aq})$ ion pairs at each of these three concentrations. We examined the effects of sAg-MNPs in addition to unsulfidated Ag-MNPs. Further, as unsulfidated $\mathrm{Ag}-\mathrm{MNPs}$ are prone to dissolution and release of free $\mathrm{Ag}^{+}, \mathrm{AgNO}_{3}\left(\mathrm{Ag}^{+}\right)$was used as an ion control in all experiments.

\section{Dissolution Experiments}

Dissolution was determined by centrifuging $2.0 \mathrm{~mL}$ samples in MHRW at 16,800g in polypropylene microcentrifuge tubes for 3 hours after 1 and 24 hour incubation at $20^{\circ} \mathrm{C}$ in darkness. Stoke's law predicts that this sedimented Ag-MNPs larger than $1 \mathrm{~nm}$ in diameter. $\mathrm{AgNO}_{3}$ controls (at $10 \mu \mathrm{g} \mathrm{Ag} \mathrm{L}^{-1}$ ) were also used to account for any ion loss during centrifugation. We measured dissolution of Ag-MNPs and sAg-MNPs at two concentrations of 
108

109

110

111

112

113

114

115

116

117

118

119

120

121

122

123

124

125

126

127

128

129

1.5 and $0.05 \mathrm{mg} \mathrm{Ag} \mathrm{L}^{-1}$. Immediately after centrifugation, the top $1 \mathrm{~mL}$ of supernatant was removed and adjusted to $0.12 \mathrm{M} \mathrm{HCl}$. One $\mathrm{mL}$ of non-centrifuged samples was digested in $9 \mathrm{~mL}$ of concentrated $\mathrm{HNO}_{3}$ and $3 \mathrm{~mL}$ of concentrated $\mathrm{HCl}$, heated in a microwave to $100^{\circ} \mathrm{C}$, held at that temperature for $10 \mathrm{~min}$, and diluted to final acid concentration of $0.45 \mathrm{M} \mathrm{HNO}_{3} / 0.012 \mathrm{M}$ $\mathrm{HCl}$ for analysis. Samples were analyzed for Ag using inductively coupled plasma mass spectrometry (ICP-MS) (Agilent 7500cx, Santa Clara, CA) with duplicate digestions, matrix spikes, cross calibration verification, and reagent blanks.

\section{Nematode exposure and toxicity experiments}

The toxicity protocols employed represent modifications of previously established $C$. elegans toxicity testing methods (Williams and Dusenbery, 1988, 1990) and those previously used in our lab (Tsyusko et al., 2012b) with modifications stated below.

Wild type N2 Bristol strain of C. elegans was obtained from the Caenorhabditis Genetics Center and were age-synchronized using $\mathrm{NaClO} / \mathrm{NaOH}$ solution (Williams and Dusenbery, 1988). Mortality with feeding, growth, and reproduction experiments were conducted in the presence of bacterial food, Escherichia coli (OP50 strain), was added $\left(\mathrm{OD}_{600}=1\right)$ at the rate of $10 \mu \mathrm{L} \mathrm{mL} \mathrm{L}^{-1}$ of exposure solution. Exposure solutions for growth and reproduction experiments were replaced after $24 \mathrm{~h}$ and fresh bacterial food was added.

Mortality. For mortality testing, larval L3 stage nematodes were exposed to varying concentrations of Ag-MNPs, sAg-MNPs, and $\mathrm{AgNO}_{3}$ in $\mathrm{MHRW}$ with and without bacterial food for $24 \mathrm{~h}$ in a 24 well polycarbonate tissue culture plate. At least five concentrations were used

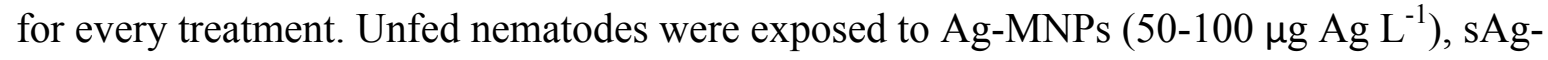
MNPs (250-1500 $\left.\mu \mathrm{g} \mathrm{Ag} \mathrm{L}{ }^{-1}\right)$, and $\operatorname{AgNO}_{3}\left(2.5-10 \mu g \mathrm{Ag} \mathrm{L}^{-1}\right)$; fed nematodes were exposed to 
Ag-MNP (1000-4500 $\left.\mu \mathrm{g} \mathrm{Ag} \mathrm{L}{ }^{-1}\right), \operatorname{sAg-MNP}\left(2000-10,000 \mu g \operatorname{Ag~L}^{-1}\right)$, and $\operatorname{AgNO}_{3}(25-85 \mu g \mathrm{Ag}$

$\mathrm{L}^{-1}$ ). Exposures without feeding were conducted to differentiate between mortality due to dissolution and mortality due to intact particles, where dissolution and subsequent binding of $\mathrm{Ag}^{+}$ions to microbial cells would have complicated interpretation(Levard et al., 2014).

\section{Dissolution rates after 24 hours at each concentration of Ag-MNP and sAg-MNP were} determined using the methods described above. The calculated amount of Ag+ present in the solution at every concentration were then compared to the mortality concentration-response curve for $\mathrm{Ag}^{+}$to identify the level of mortality caused by that concentration of $\mathrm{Ag}^{+}$. Experiments with feeding were conducted to establish ranges for growth and reproduction experiments. Feeding is necessary to prevent dauer formation at early stages of larval development in growth and reproduction assays. Each treatment had 4 replicates per concentration with $10( \pm 1)$ nematodes in each well and all concentrations were tested in two independent experiments.

Growth. Eggs were hatched in the exposure solutions made with MHRW with OP50 food source $\left(10 \mu \mathrm{L} \mathrm{mL}{ }^{-1}\right)$. Nematodes were exposed in $15 \mathrm{~mL}$ centrifuge tubes with $4 \mathrm{~mL}$ of the exposure medium; Ag-MNPs (500-3000 $\mu \mathrm{g} \mathrm{Ag} \mathrm{L}^{-1}$ ), sAg-MNP (3000-9000 $\mu \mathrm{g} \mathrm{Ag} \mathrm{L}^{-1}$ ), and $\mathrm{AgNO}_{3}(6.25$ $30 \mu \mathrm{g} \mathrm{Ag} \mathrm{L}^{-1}$ ) in MHRW. Nematode body length was measured after 48 hours. Nematodes were allowed to settle for $30 \mathrm{~min}$ and at least 30 nematodes were removed from exposures and treated with sodium azide ( $3 \mu \mathrm{L}$ of $170 \mathrm{mM}$, to straighten them) and imaged using a light microscope. Measurements were then made using NIS-Elements BR 3.0 image processing software (Nikon). Each concentration was tested in two independent experiments.

Reproduction. Eggs were hatched on K-agar plates with OP50 bacterial lawns (Williams and Dusenbery, 1988) and were placed into the exposure solutions. For each exposure, six L1 
152 nematodes were exposed to at least five concentrations per treatment of Ag-MNPs (250-1000 $\mu \mathrm{g}$

$\left.153 \mathrm{Ag} \mathrm{L}{ }^{-1}\right)$, sAg-MNPs (1000-5000 $\left.\mu \mathrm{g} \mathrm{Ag} \mathrm{L}{ }^{-1}\right)$, and $\operatorname{AgNO}_{3}\left(5-25 \mu g \mathrm{Ag} \mathrm{L}^{-1}\right)$ in MHRW. After $50 \mathrm{~h}$

154 of exposure, individual nematodes were transferred to K-agar plates for egg laying. Adult

155 worms were transferred to fresh K-Agar plates every $24 \mathrm{~h}$ for $72 \mathrm{~h}$. Plates were incubated for 24

$156 \mathrm{~h}$ to allow hatching, then stained with rose bengal $\left(0.5 \mathrm{mg} \mathrm{L}^{-1}\right)$, heated to $50^{\circ} \mathrm{C}$ for $55 \mathrm{~min}$, then

157 fully hatched juveniles were counted. Each exposure was tested in two independent

158 experiments.

\section{Particle-specific effects versus Ion-specific effects}

To determine the effect of $\mathrm{Ag}^{+}$produced by the Ag-MNPs and sAg-MNPs, particle free

161 supernatants were generated after $24 \mathrm{~h}$ incubation and prepared as described above in the

162 dissolution experiment section. Nematodes exposed to particle free supernatants were compared

163 to nematodes exposed to whole suspensions that had been incubated for $24 \mathrm{~h}$. Concentrations

164 above the $\mathrm{LC}_{50}$ were selected for all treatments, and exposure conditions were the same as in the 165 experiments for mortality without feeding.

Synchrotron x-ray fluorescence microscopy

Distribution of Ag was examined in L4 stage C. elegans exposed to $\mathrm{Ag}^{+}\left(10 \mu \mathrm{g} \mathrm{L}^{-1}\right), \mathrm{Ag}^{-}$

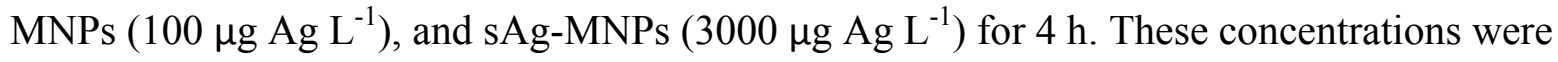
selected because relatively high tissue concentrations are required for detection by X-ray

170 fluorescence and because they resulted in similar mortality after $4 \mathrm{~h}$ of exposure $(\sim 30 \%)$.

171 Approximately 100-150 nematodes were collected, washed twice with MHRW, and preserved in $17220 \%$ ethanol prior to X-ray analysis. Scanning X-ray fluorescence microscopic measurements

173 were performed at sectors 13 and 20 at the Advanced Photon Source, Argonne National

174 Laboratory (Lemont, IL, USA). Additional details on synchrotron methods are provided in SI. 


\section{Statistical Methods}

For growth, reproduction, and mortality, means and standard errors were calculated per treatment and concentration. Probit analysis using the PROBIT procedure in SAS v9.3 (SAS Institute, Cary, $\mathrm{NC}$, USA) was used to determine the $\mathrm{LC}_{10}$ and $\mathrm{LC}_{50}$ values, presented at $95 \%$ confidence intervals. To test whether the observed mortality was due to particle specific effects or simply due to the release of $\mathrm{Ag}^{+}$into solution, student's t-tests were used to compare the mortality of nematodes exposed to particle free supernatants and those exposed to the whole suspensions. Student's t-tests with Dunnett's multiple comparison corrections were applied to test whether each concentration within a treatment was significantly different from control for all experiments. Homogeneity of variance and normality of errors assumptions were checked using Q-Q plots and studentized residual plots. $\mathrm{EC}_{10}$ and, when appropriate, $\mathrm{EC}_{50}$ values were calculated from parameters determined using linear regression. SAS v9.3 was used for all statistical analyses and SigmaPlot 12.3 (Systat, San Jose, CA, USA) was used to generate all figures.

\section{Results}

\section{Characterization and Dissolution Measurements}

We observed that the zeta potential of the Ag-MNPs decreased with sulfidation from -6.1 $\mathrm{mV}$ for Ag-MNPs to $-28.1 \mathrm{mV}$ for sAg-MNP. However, the size of the MNPs changed less than $10 \%$ with sulfidation when measured by TEM, $58.3 \pm 12.9 \mathrm{~nm}$ (mean \pm standard deviation) for Ag-MNPs and $64.5 \pm 19.4 \mathrm{~nm}$ for sAg-MNPs. A similar change was observed in the z-average hydrodynamic diameter, for Ag-MNPs $79.6 \pm 0.5$ and $88.5 \pm 0.5$ for sAg-MNP. The TEM images (SI1) and DLS particle size distributions (intensity and volume weighted) in MHRW (SI2 and SI3) corresponding to the data described above are provided in the supplemental information 
(SI). For both Ag-MNPs and sAg-MNPs the dissolved Ag, expressed as a \% of the total, was

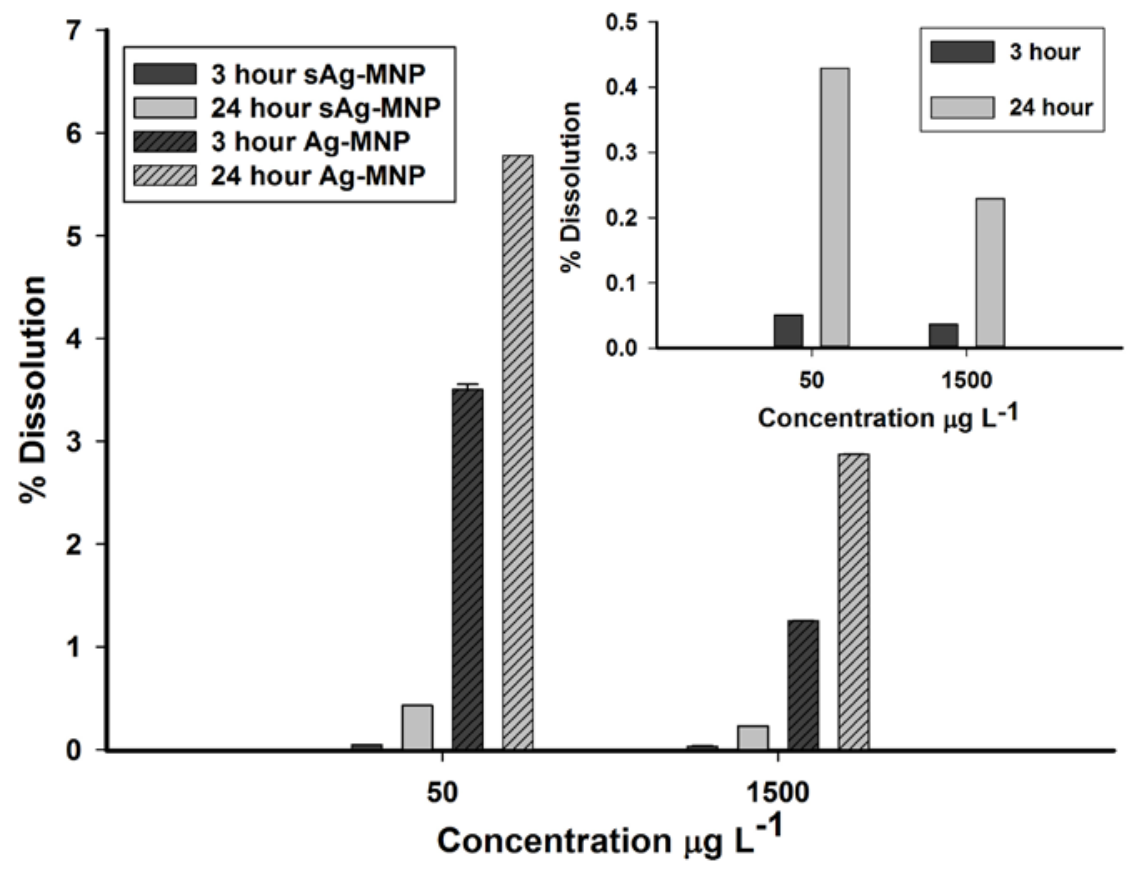

204

205

Figure 1. The percent dissolution of pristine silver manufactured nanoparticles (Ag-MNP) and artificially aged silver manufactured nanoparticles (sAg-MNP) at 3 and 24 hours at two concentrations (50 and $1500 \mu \mathrm{g} \mathrm{L}^{-1}$ ) in moderately hard reconstituted water (Main) and sAg-MNP (Insert) at full scale. Error bars represent the minimum and maximum total Ag concentration.

207

For the sAg-MNP the dissolved $\mathrm{Ag}$ at $3 \mathrm{~h}$ was found to be $0.05 \%$ and $0.03 \%$ for 50 and $1500 \mu \mathrm{g}$

208 $\mathrm{L}^{-1}$, respectively, and was found to be $0.43 \%$ and $0.23 \%$ at $24 \mathrm{~h}$ for 50 and $1500 \mu \mathrm{g} \mathrm{L}^{-1}$, and 12-fold at $50 \mu \mathrm{g} \mathrm{L}^{-1}$ and $1500 \mu \mathrm{g} \mathrm{L}^{-1}$, respectively, compared to Ag-MNPs. 


\section{Toxicity and Bioavailability}

Reproduction was found to be the most sensitive endpoint tested while growth was the

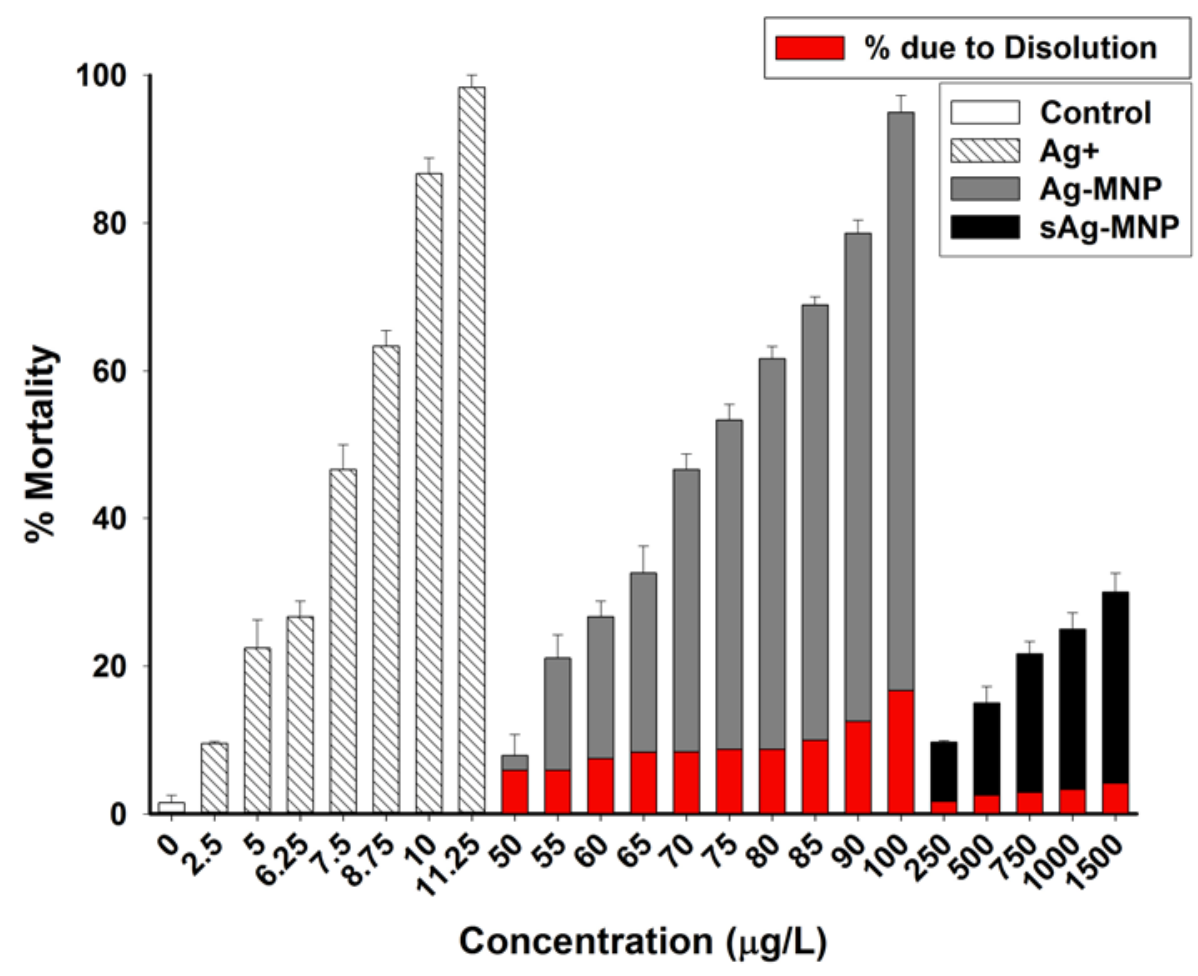

Figure 2. Mortality of Caenorhabditis elegans after 24 hours without feeding exposure to $\mathrm{Ag}^{+}$, pristine silver manufactured nanoparticles (Ag-MNP), and artificially aged manufactured nanoparticles (sAg$\mathrm{MNP}$ ) in moderately hard reconstituted water. Red portions of Ag-MNP and sAg-MNP bars represent the amount of mortality that can be attributed to their dissolution. Data are presented as mean percent mortality with error bars indicating standard error of the mean. Mortality at all concentrations was found to be significantly greater than control $(\mathrm{p}<0.001)$, except for $\mathrm{Ag}^{+} 2.5 \mu \mathrm{g} \mathrm{L}$, Ag-MNP $50 \mu \mathrm{g} \mathrm{L}$ ${ }^{1}$, and sAg-MNP $250 \mu \mathrm{g} \mathrm{L}{ }^{-1}$. 
226 The concentrations at which $C$. elegans exhibited equivalent mortality were 4 to 30 fold higher in

227 the experiment with feeding than without feeding at the $\mathrm{LC}_{10}$. The $\mathrm{LC}_{10}(95 \% \mathrm{CI})$ for $\mathrm{Ag}^{+}, \mathrm{Ag}^{-}$

228 MNPs, and sAg-MNPs were $24.8(12.83,33.94) \mu g \mathrm{~L}^{-1}, 2002 \mu \mathrm{g} \mathrm{L}{ }^{-1}$, and $4106 \mu \mathrm{g}(2442,6072)$

$229 \mathrm{~L}^{-1}$, respectively, for fed organisms. The $\mathrm{LC}_{50}(95 \% \mathrm{CI})$ for $\mathrm{Ag}^{+}$was $54.8(43.31,63.40) \mu \mathrm{g} \mathrm{L}$ and for Ag-MNP was $3119(2976,3262) \mu g \mathrm{~L}^{-1}$.

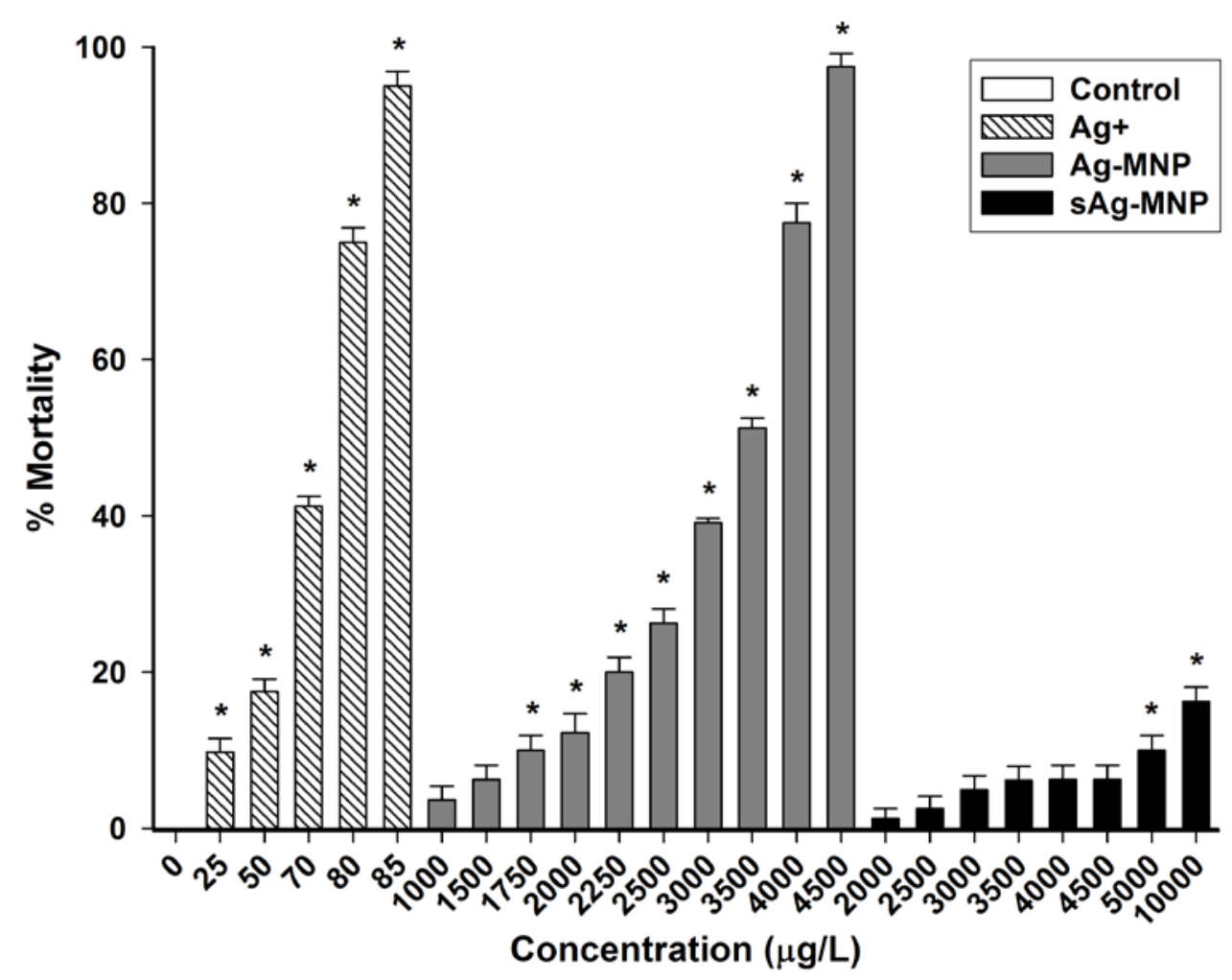

Figure 3. Mortality of Caenorhabditis elegans after 24 hours in the presences of bacterial food (Escherichia coli strain OP50) when exposed to $\mathrm{Ag}^{+}$, pristine silver manufactured nanoparticles (AgMNP), and artificially aged manufactured nanoparticles (sAg-MNP) in moderately hard reconstituted water. Data are presented as mean percent mortality with error bars indicating standard error of the mean. * Indicate treatments found to be significantly different than control $(\mathrm{p}<0.001)$.

235 Nematodes exposed to $10,000 \mu \mathrm{g} \mathrm{L}^{-1}$, the highest concentration of sAg-MNP tested, only resulted in an observed mortality of 20\% (Fig. 3). 
237 Particle versus Ion Specific mortality. Except for the $50 \mu \mathrm{g} \mathrm{L}{ }^{-1}$ Ag-MNP treatment, the mortality

238 observed at all other concentrations cannot be fully explained by dissolution and release of $\mathrm{Ag}^{+}$

239 for both Ag-MNPs and sAg-MNPs (Fig. 2). The proportion of mortality attributable to ion

240 release from MNPs into the exposure medium as measured by the dissolution experiments over

$24124 \mathrm{~h}$, decreased with increasing exposure concentration for both Ag-MNPs and sAg-MNPs. The

242 mortalities for the nematodes exposed to each particle free supernatants of Ag-MNPs and sAg-

243 MNPs were less than 10\% and were not significantly different from that in controls, while

244 mortality in the whole suspensions were at 78\% for Ag-MNPs and 62\% for sAg-MNPs (Fig. 4).

245 When the nematodes were exposed to supernatants of $\mathrm{Ag}^{+}$the mortality was $85 \%$, similar to the

$24688 \%$ mortality observed in the whole (uncentrifuged) $\mathrm{Ag}^{+}$solution $(p=0.2554)$. The mortality

247 estimates for the Figures 2 and 4 were derived from two independent experiments, which explain

248 slight variation in responses at the same concentrations.

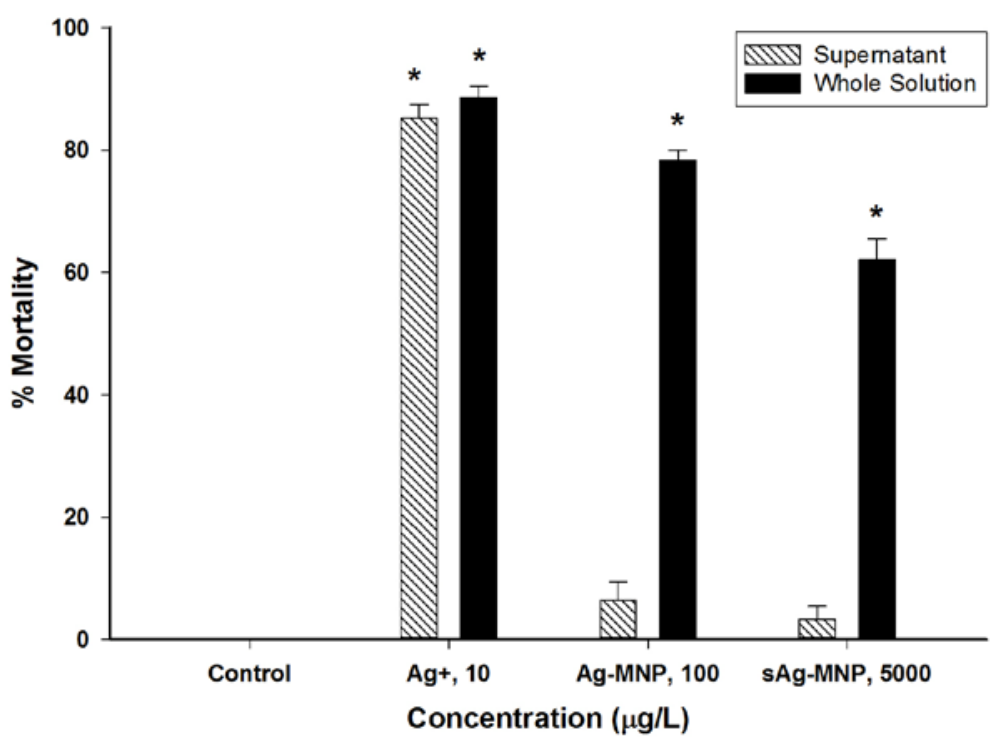

Figure 4. Mortality of Caenorhabditis elegans after 24 hours without feeding when exposed to particle free supernatants (Supernatant) versus whole solutions of $\mathrm{Ag}^{+}$, pristine silver manufactured nanoparticles (Ag-MNP), and artificially aged manufactured nanoparticles (sAg-MNP) (Whole

251 Solution) in moderately hard reconstituted water. Data are presented as mean percent mortality with error bars indicating standard error of the mean. * Indicate treatments found to be significantly different than control $(\mathrm{p}<0.001)$. 
Growth. Nematodes exposed to $\mathrm{Ag}^{+}, \mathrm{Ag}-\mathrm{MNPs}$, and sAg-MNPs all exhibited significantly shorter body lengths compared to control, regardless of concentration $(\mathrm{P}<0.001$ for all comparisons) (Fig. 5) . The greatest decrease from the control in mean body length was observed in $\mathrm{Ag}^{+}$exposed nematodes, followed by $\mathrm{Ag}-\mathrm{MNP}$ exposed nematodes, with the smallest decrease in response to sAg-MNP exposed nematodes. These significant decreases were observed at every concentration tested versus controls $(\mathrm{p}<0.001)$ The $\mathrm{EC}_{10}$ for $\mathrm{Ag}^{+}, \mathrm{Ag}-\mathrm{MNPs}$ and sAg-MNPs were $6.6 \mu \mathrm{g} \mathrm{L}^{-1}, 1118 \mu \mathrm{g} \mathrm{L}{ }^{-1}$, and $5946 \mu \mathrm{g} \mathrm{L}{ }^{-1}$, respectively.

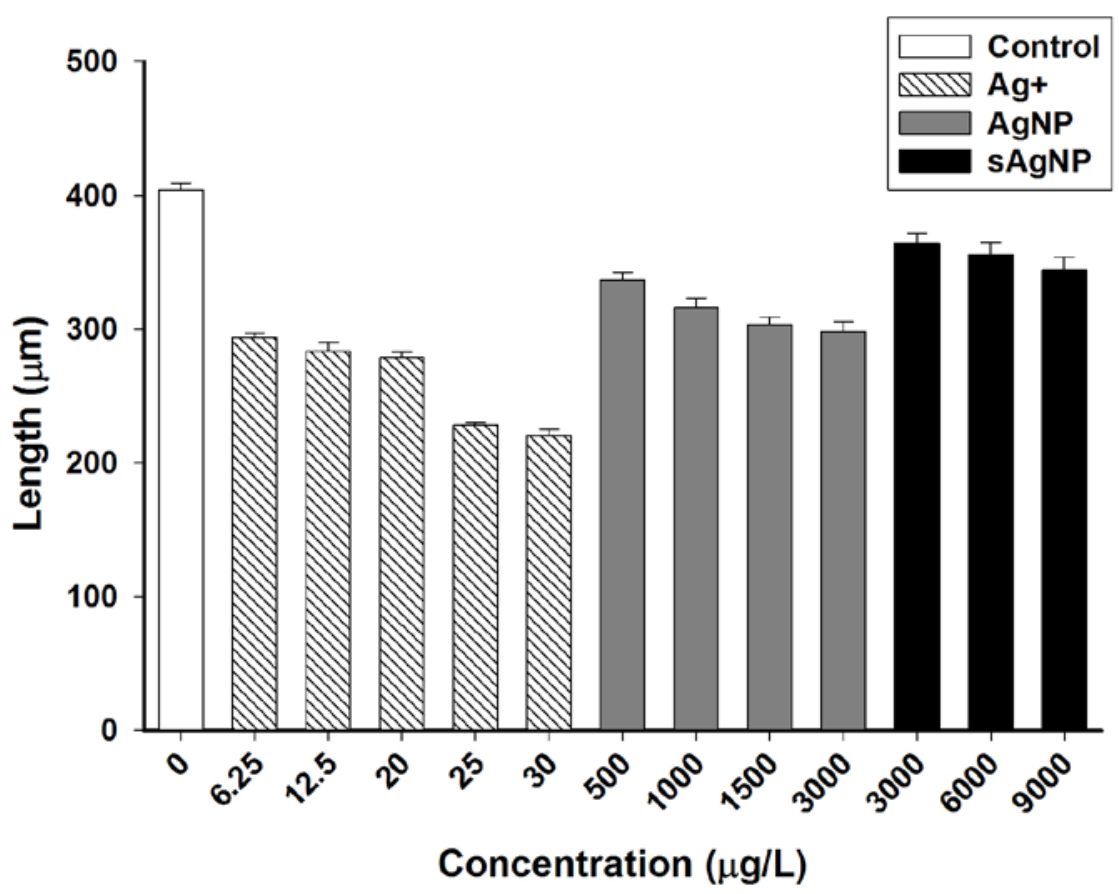

Figure 5. Observed mean body length of Caenorhabditis elegans measured after 48 hours from L1 stage exposed to $\mathrm{Ag}^{+}$, pristine silver manufactured nanoparticles (Ag-MNP), and artificially aged manufactured nanoparticles (sAg-MNP) in moderately hard reconstituted water in the presence of bacterial food (Escherichia coli strain OP50). Data are presented as mean percent mortality with error bars indicating standard error of the mean. All concentrations were found to be significantly different than control $(\mathrm{p}<0.001)$.

Reproduction. Nematodes exposed to $\mathrm{Ag}^{+}, \mathrm{Ag}-\mathrm{MNPs}$, and sAg-MNPs exhibited significant decrease in number of offspring per adult compared to control, regardless of concentration ( $\mathrm{p}<$ 0.001 for all comparisons) (Fig. 6) Nematodes exposed to sAg-MNPs had a significantly higher 
average number of offspring per adult than those exposed to $\mathrm{Ag}^{+}(\mathrm{p}=0.015)$ or $\mathrm{Ag}-\mathrm{MNPs}(\mathrm{p}=$ 0.004), regardless of concentration. The $\mathrm{EC}_{10}$ for $\mathrm{Ag}^{+}$was $3.1 \mu \mathrm{g} \mathrm{L}-1$ and $\mathrm{EC}_{10}$ for $\mathrm{Ag}-\mathrm{MNPs}$ and sAg-MNPs were $113.1 \mu \mathrm{g} \mathrm{L}^{-1}$ and $802.4 \mu \mathrm{g} \mathrm{L}^{-1}$, respectively. The $\mathrm{EC}_{50}$ for $\mathrm{Ag}^{+}$was $15.3 \mu \mathrm{g} \mathrm{L}{ }^{-1}$, for Ag-MNPs was $566 \mu g \mathrm{~L}^{-1}$, and for the sAg-MNPs it was $4011 \mu \mathrm{g} \mathrm{L}^{-1}$.

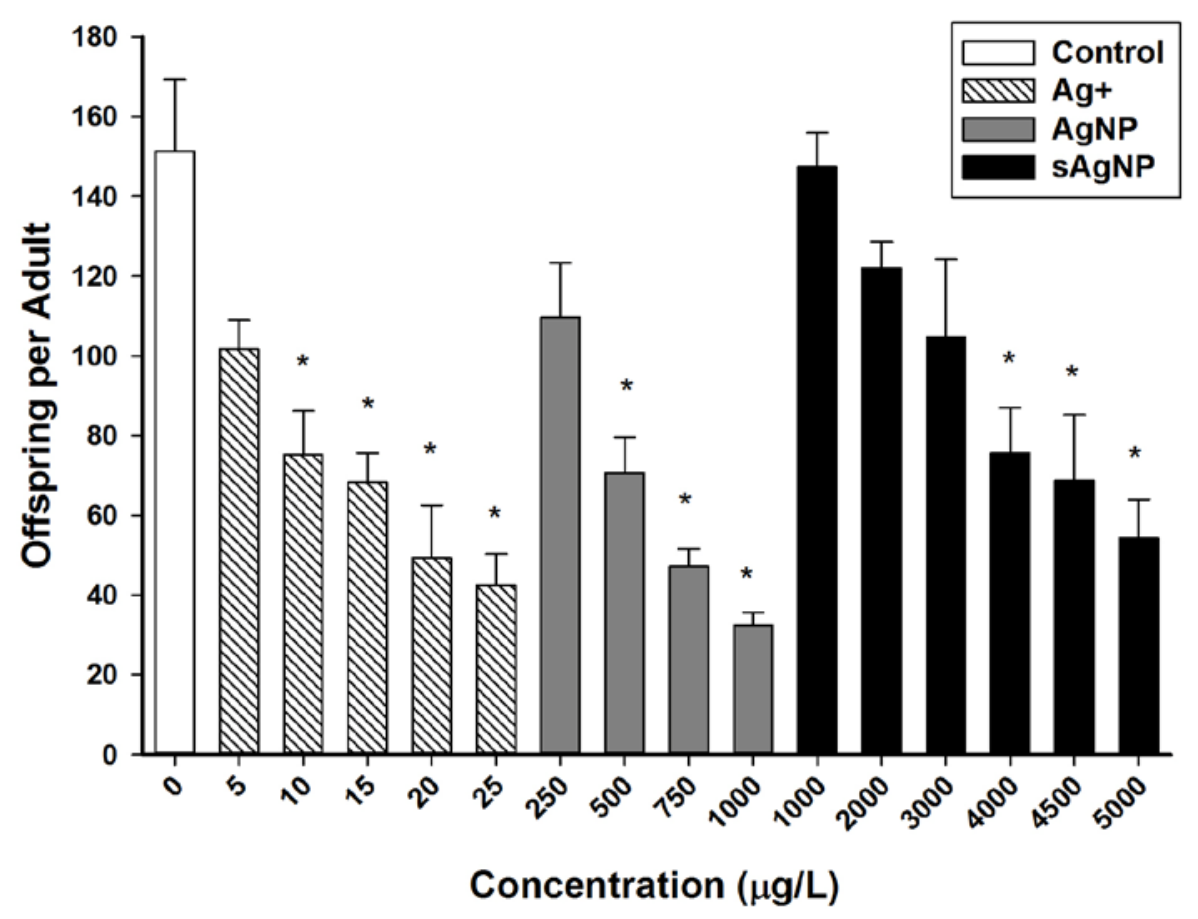

Figure 6. Mean total number of offspring per adult nematode Caenorhabditis elegans after 48 hours from $\mathrm{L} 1$ stage exposed to $\mathrm{Ag}^{+}$, pristine silver manufactured nanoparticles (Ag-MNP), and artificially aged silver manufactured nanoparticles (sAg-MNPs) in moderately hard reconstituted water in the presence of bacterial food (Escherichia coli strain OP50). Data are presented as mean percent mortality with error bars indicating standard error of the mean. * Indicate treatments found to be significantly different than control $(\mathrm{p} \leq 0.001)$.

Bioavailability. From $\mu$-XRF Ag fluorescence intensity maps of C. elegans exposed to $\mathrm{Ag}^{+}, \mathrm{Ag}$ MNPs, and sAg-MNP at approximately $\mathrm{LC}_{30}$ concentrations (estimated after $4 \mathrm{hrs}$ of exposure), lower intensities of $\mathrm{Ag}$ were observed in sAg-MNP treatment than $\mathrm{Ag}^{+}$or $\mathrm{Ag}-\mathrm{MNP}$ treatments. Nematodes exposed to $\mathrm{Ag}^{+}$and $\mathrm{Ag}-\mathrm{MNPs}$ showed similar spatial distributions and emission intensities for $\mathrm{Ag}$ (Fig. 7). Tissue concentrations were too low to collect x-ray absorption spectroscopic data to determine speciation. 

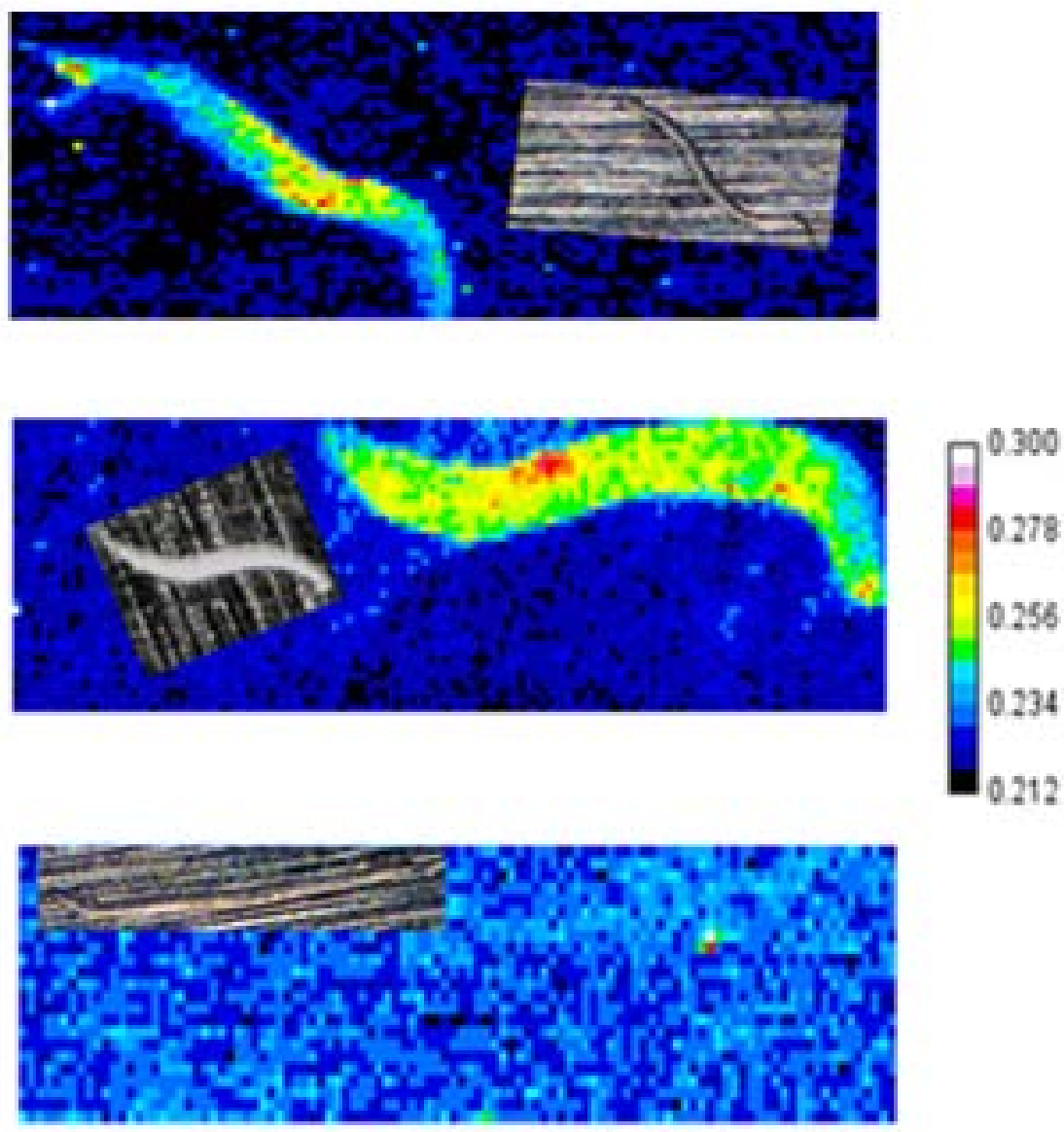

Figure 7. Ag K $\alpha 1$ fluorescence of Caenorhabditis elegans specimens (stage L4) that were exposed to $\mathrm{LC}_{30}$ (at $4 \mathrm{hr}$ ) for $\mathrm{Ag}^{+}$(Top), pristine silver manufactured nanoparticles (Middle), and artificially aged silver manufactured nanoparticles (Lower) in moderately hard reconstituted water in the absence of bacterial food, as determined using a synchrotron-based X-ray fluorescence microprobe. Color bar indicates normalized Ag K $\alpha 1$ fluorescence intensity. The data are normalized to the incident beam ion chamber reading, so they are normalized with respect to each other.

\section{Discussion}

Importantly, our results demonstrate that it is not just the decrease in solubility of $\operatorname{Ag}_{2} \mathrm{~S}$ relative to $\mathrm{Ag}(0)$ that accounts for the observed reductions in toxicity, but also a decrease in the

287 uptake of intact sAg-MNPs resulting in decreased particle-specific effects of sAg-MNPs compared to pristine $\operatorname{Ag}(0)$-MNPs (vide infra). Whether the observed toxicological effects of Ag-MNPs are due to particle-specific effects, or simply due to the release of $\mathrm{Ag}^{+}$into solution 
290 has been a matter of debate since the first reports of Ag MNP toxicity (Xiu et al., 2012; Yang et al., 2012; Yin et al., 2011). Using multiple experimental approaches, we demonstrate that undissolved particles in the exposure media cause toxicity. Although it is likely that dissolution 293 of the particles following uptake elicits toxicity through the release of ions, we consider this 294 route of cellular uptake and tissue specific delivery to be particle-specific (Tsyusko et al., 295 2012a). It is also possible that presence of the nematodes or food can promote dissolution of Ag296 MNPs. If, the released dissolved Ag is immediately bound to ligands in the nematodes and the 297 food, the Ag-MNPs would release more dissolved Ag to maintain the equilibrium between 298 dissolved and particulate Ag. This could lead to an underestimation of the effects due to 299 dissolved ions. From previously published data, there appears to be an emerging agreement that 300 the toxic effects of Ag-MNPs are due in part to the release of $\mathrm{Ag}^{+}$and in part from particle 301 effects during exposure (Ellegaard-Jensen et al., 2012; Kim et al., 2012; Meyer et al., 2010). The 302 results of this study also support this emerging paradigm. Recently, Croteau et al. suggested that 303 bioaccumulation due to the release of ions is concentration dependent in snails (Croteau et al., 304 2014). However, we believe that this is among the first studies to clearly demonstrate that the 305 relative importance of dissolution and release of $\mathrm{Ag}^{+}$in the exposure media for toxicity is 306 concentration dependent. Therefore, it is likely that some previous conflicting reports 307 concerning the importance of dissolution may be due to differences in exposure concentration 308 (Xiu et al., 2012; Yang et al., 2012). Although we observed that sulfidation of Ag-MNPs greatly 309 reduces the amount of $\mathrm{Ag}^{+}$released and associated toxicity at any of the concentrations tested, a 310 large proportion of the effects of sAg-MNPs observed in this study were particle specific. The 311 reduction in the release of $\mathrm{Ag}^{+}$as a result of sulfidation has been reported (Levard et al., 2013a; 312 Levard et al., 2012; Levard et al., 2011; Liu et al., 2011); however, we believe this to be the first 
313 report demonstrating particle specific effects of sAg-MNPs. The role of sAg-MNPs was not

314 simply a continuing source of dissolved ions to be scavenged by ligands in the nematodes, since

315 the XRF imaging indicated that at LC30 for mortality, there are different amounts of Ag

316 accumulated from each treatment indicating that the toxicity was not associated with equivalent

$317 \mathrm{Ag}$ body burdens as for the $\mathrm{AgNO}_{3}$ or $\mathrm{Ag}-\mathrm{MNP}$ treatments.

Meyer et al. (2010) demonstrated that C. elegans are able to internalize Ag-MNPs with

319 different coatings and smaller size than the Ag-MNPs we tested and also our results are in 320 agreement with other paper from the same group where sulfidation significantly decreased

321 toxicity (Levard et al. 2013a), but the effects on reproduction and differences in bioavailability

322 were not investigated by the authors(Meyer et al., 2010). The lowered particle specific toxicity

323 of sAg-MNPs compared to Ag-MNPs can be in part explained by their decreased bioavailability,

324 as was observed from the synchrotron based X-ray fluorescence images. The Ag concentrations

325 in the nematodes exposed to the $\mathrm{sAg}-\mathrm{MNPs}$ at $\mathrm{LC}_{30}$ were below the XRF detection limit. In

326 contrast, internal $\mathrm{Ag}$ concentrations in nematodes treated with $\mathrm{AgNO}_{3}$ and $\mathrm{Ag}-\mathrm{MNPs}$ were

327 readily detectable suggesting that the particle specific toxicity elicited by sAg-MNPs may not

328 involve uptake. A less likely alternative hypothesis is that it is caused by very low tissue

329 concentrations of sAg-MNPs that were below the XRF detection limit. The toxicity is also not

330 explained by soluble impurities, coatings, or other decomposition products released from the

331 sAg-MNPs since particle free supernatants caused minimal mortality. One possible mechanism

332 by which sAg-MNPs could cause an effect in the absence of uptake is through cuticle damage,

333 since the cuticle serves as a primary defense of the nematode against environmental stressors

334 (Cox et al., 1981; Handy et al., 2012; Kim et al., 2012). 
Although there have been several investigations into the effects that the exposure medium

has on the toxicity of Ag-MNPs, little attention has been paid to the presences/absence of a food source on toxicity(Yang et al., 2014). We expected there to be a decrease in the toxicity in the presence of bacterial food as the nematodes being fed should have increased resistance to the stress caused by Ag-MNP exposure and because partitioning of particles and the released Ag ions to bacteria could also be anticipated to reduce toxicity. Our results show that the addition of bacterial food decreased the toxicity in contrast to Ellegaard-Jensen et al., (2012) who found an opposite effect. They speculated that bacteria represent a dietary exposure route via trophic transfer. Higher ionic strength media have been shown to decrease toxicity of Ag-MNPs (Levard et al., 2013b; Tyne et al., 2013; Yang et al., 2012). We used a different exposure medium (MHRW) than Ellegaard-Jensen et al., (2012) who utilized K-meduma, which has approximately a 3-fold higher ionic strength that MHRW. Additionally, the study of EllegaardJensen et al., (2012) used $28 \mathrm{~nm}$ Ag-MNPs that were also coated with PVP but were approximately three times smaller than the Ag-MNPs used in our study. The solubility(Ma et al., 2012) and dissolution rate of Ag MNPs increases with decreasing size (Zhang et al., 2011b). These differences may explain in part the discrepancy between the studies.

We are unaware of any other investigations that have examined both the bioavailability and toxicity of Ag-MNPs and sAg-MNPs for three ecologically relevant endpoints in C. elegans. Our experimental approach also allowed us to tease out the relative importance of particle specific versus ion specific effects for Ag-MNPs and sAg-MNPs. Our results combined with those of Levard et al. (2013) demonstrate that aging of Ag-MNPs in the presence of sulfide reduces toxicity as measured by both mortality and growth (Levard et al., 2013a). The results of

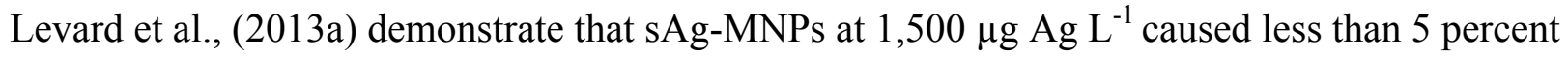




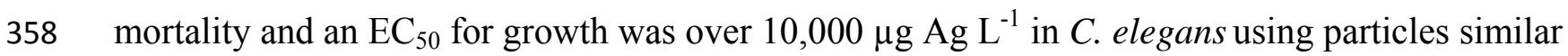
359 to sAg-MNPs we employed. However, the impact of sAg-MNPs on reproduction in C. elegans, 360 which is the most sensitive endpoint we examined, has not been previously reported.

Overall, these results demonstrate greatly reduced toxicity of sAg-MNPs as compared to

362

363

364

365

366

367

368

369

370

371

372

373

374

375

\section{Acknowledgments}

Funding for this research was provided by the United States Environmental Protection

378

379

Ag-MNPs, suggesting that transformation via the WWTP would likely result in a greatly reduced toxicity of Ag-MNPs. This indicates that hazards of Ag-MNP exposure are likely greater in applications where Ag-MNPs are introduced directly to soil rather than through biosolids application. For example, Ag-MNPs are being researched for use as pesticides or as pesticide delivery vehicles (Marimuthu et al., 2011; Santhoshkumar et al., 2011). However, Ag-MNPs that are introduced as unsulfidized materials are quickly sulfidated in reducing environments such as freshwater sediment(Lowry et al., 2012). The recognition that the relative importance of particle specific effects are concentration dependent may also bring some clarity to observed inconsistencies in the literature. Finally, it is apparent from this study, that sAg-MNPs may elicit toxicity independent of $\mathrm{Ag}^{+}$ion release. Whitley et al. (2013) observed that sAg-MNPs were present in pore water of soils amended with Ag-MNP spiked biosolids. Although particle specific toxicity of sAg-MNPs is not great in C. elegans, it would be prudent to test the toxicity of sAg-MNPs in other receptor species and in food chain exposures where significant dissolution could occur in the gastrointestinal systems of certain ecoreceptors.

Funding for this research was provided by the United States Environmental Protection Agency (U.S. EPA) (RD 834574). JU, GL and OT are supported by the U.S. EPA and National Science Foundation (NSF) through cooperative agreement EF-0830093, Center for 
Environmental Implications of Nanotechnology (CEINT). Any opinions, findings, conclusions, or recommendations expressed in this material are those of the author(s) and do not necessarily reflect the views of the EPA or NSF. This work has not been subjected to EPA or NSF review, and no official endorsement should be inferred. Caenorhabditis elegans N2 strain was purchased from the Caenorhabditis Genetics Center. Portions of this work were performed a GeoSoilEnviroCARS (Sector 13), Advanced Photon Source (APS), Argonne National Laboratory and PNC/XSD (Sector 20). GeoSoilEnviroCARS is supported by the National Science Foundation-Earth Sciences (EAR-1128799) and Department of Energy-GeoSciences (DE-FG02-94ER14466). PNC/XSD facilities are supported by the US Department of Energy Basic Energy Sciences, a Major Resources Support grant from NSERC, the University of Washington, the Canadian Light Source and the Advanced Photon Source. Use of the APS was supported by the U.S. Department of Energy, Office of Science, Office of Basic Energy Sciences, under Contract No. DE-AC02-06CH11357.

Statistical support was provided by the Applied Statistics Lab and the Center for Clinical and Translational Science (CCTS) at the University of Kentucky. The CCTS is supported by grant number UL1TR000117 from the National Center for Advancing Translational Sciences (NCATS), funded by the Office of the Director, National Institutes of Health (NIH) and supported by the NIH Roadmap for Medical Research.

\section{References}

Benn, T., Westerhoff, P., 2008. Nanoparticle silver released into water from commercially available sock fabrics. Environ Sci Technol 42, 4133-4139. Blaser, S.A., Scheringer, M., Macleod, M., Hungerbuhler, K., 2008. Estimation of cumulative aquatic exposure and risk due to silver: contribution of nano-functionalized plastics and textiles. Sci Total Environ 390, 396-409. 
Chen, X., Schluesener, H.J., 2008. Nanosilver: a nanoproduct in medical application. Toxicol Lett 176, 1-12.

406 Cheng, Y., Yin, L., Lin, S., Wiesner, M., Bernhardt, E., Liu, J., 2011. Toxicity Reduction of Polymer-Stabilized Silver Nanoparticles by Sunlight. J. Phys. Chem. C 115, 4425-4432. Choi, J., Tsyusko, O., Unrine, J., Chatterjee, N., Ahn, J.-M., Yang, X., Thornton, L., Ryde, I., Starnes, D., Meyer, J., 2014. A micro-sized model for the in vivo studies of nanoparticle toxicity: What has Caenorhabditis elegans taught us? Envir. Chem. 11, 227-246.

Choi, O., Hu, Z., 2008. Size dependent and reactive oxygen species related nanosilver toxicity to nitrifying bacteria. Environ Sci Technol 42, 4583-4588.

Collin, B., Oostveen, E., Tsyusko, O.V., Unrine, J.M., 2014. Influence of natural organic matter and surface charge on the toxicity and bioaccumulation of functionalized ceria nanoparticles in Caenorhabditis elegans. Environ Sci Technol 48, 1280-1289.

Cox, G.N., Staprans, S., Edgar, R.S., 1981. The cuticle of Caenorhabditis elegans. II. Stagespecific changes in ultrastructure and protein composition during postembryonic development. Dev Biol 86, 456-470.

Croteau, M.N., Dybowska, A.D., Luoma, S.N., Misra, S.K., Valsami-Jones, E., 2014. Isotopically modified silver nanoparticles to assess nanosilver bioavailability and toxicity at environmentally relevant exposures. Environ Chem 11, 247-256.

Ellegaard-Jensen, L., Jensen, K.A., Johansen, A., 2012. Nano-silver induces dose-response effects on the nematode Caenorhabditis elegans. Ecotoxicol Environ Saf 80, 216-223. Fabrega, J., Fawcett, S.R., Renshaw, J.C., Lead, J.R., 2009. Silver nanoparticle impact on bacterial growth: effect of $\mathrm{pH}$, concentration, and organic matter. Environ Sci Technol 43, 7285 7290.

Gorth, D.J., Rand, D.M., Webster, T.J., 2011. Silver nanoparticle toxicity in Drosophila: size does matter. Int $\mathbf{J}$ Nanomedicine 6, 343-350.

Gottschalk, F., Scholz, R.W., Nowack, B., 2010. Probabilistic material flow modeling for assessing the environmental exposure to compounds: Methodology and an application to engineered nano-TiO2 particles. Environ. Model. Softw. 25, 320-332.

Handy, R.D., Cornelis, G., Fernandes, T., Tsyusko, O., Decho, A., Sabo-Attwood, T., Metcalfe, C., Steevens, J.A., Klaine, S.J., Koelmans, A.A., Horne, N., 2012. Ecotoxicity test methods for engineered nanomaterials: practical experiences and recommendations from the bench. Environ Toxicol Chem 31, 15-31.

Hendren, C.O., Badireddy, A.R., Casman, E., Wiesner, M.R., 2013. Modeling nanomaterial fate in wastewater treatment: Monte Carlo simulation of silver nanoparticles (nano-Ag). Sci Total Environ 449, 418-425.

Hendren, C.O., Mesnard, X., Droge, J., Wiesner, M.R., 2011. Estimating production data for five engineered nanomaterials as a basis for exposure assessment. Environ Sci Technol 45, 25622569.

Kaegi, R., Voegelin, A., Ort, C., Sinnet, B., Thalmann, B., Krismer, J., Hagendorfer, H., Elumelu, M., Mueller, E., 2013. Fate and transformation of silver nanoparticles in urban wastewater systems. Water Res 47, 3866-3877.

Kaegi, R., Voegelin, A., Sinnet, B., Zuleeg, S., Hagendorfer, H., Burkhardt, M., Siegrist, H., 2011. Behavior of metallic silver nanoparticles in a pilot wastewater treatment plant. Environ Sci Technol 45, 3902-3908.

Kim, S.W., Nam, S.H., An, Y.J., 2012. Interaction of silver nanoparticles with biological surfaces of Caenorhabditis elegans. Ecotoxicol Environ Saf 77, 64-70. 
Leung, M.C., Williams, P.L., Benedetto, A., Au, C., Helmcke, K.J., Aschner, M., Meyer, J.N., 2008. Caenorhabditis elegans: an emerging model in biomedical and environmental toxicology. Toxicol Sci 106, 5-28.

Levard, C., Hotze, E.M., Colman, B.P., Dale, A.L., Truong, L., Yang, X.Y., Bone, A.J., Brown, G.E., Jr., Tanguay, R.L., Di Giulio, R.T., Bernhardt, E.S., Meyer, J.N., Wiesner, M.R., Lowry, G.V., 2013a. Sulfidation of silver nanoparticles: natural antidote to their toxicity. Environ Sci Technol 47, 13440-13448.

Levard, C., Hotze, E.M., Lowry, G.V., Brown, G.E., Jr., 2012. Environmental transformations of silver nanoparticles: impact on stability and toxicity. Environ Sci Technol 46, 6900-6914. Levard, C., Mitra, S., Yang, T., Jew, A.D., Badireddy, A.R., Lowry, G.V., Brown, G.E., Jr., 2013b. Effect of chloride on the dissolution rate of silver nanoparticles and toxicity to E. coli. Environ Sci Technol 47, 5738-5745.

Levard, C., Reinsch, B.C., Michel, F.M., Oumahi, C., Lowry, G.V., Brown, G.E., 2011. Sulfidation processes of PVP-coated silver nanoparticles in aqueous solution: impact on dissolution rate. Environ Sci Technol 45, 5260-5266.

Levard, C., Yang, X., Meyer, J., Lowry, G., 2014. Response to Comment on "Sulfidation of silver nanoparticles: Natural antidote to their toxicity". Environ Sci Technol 48, 6051-6052. Lim, D., Roh, J.Y., Eom, H.J., Choi, J.Y., Hyun, J., Choi, J., 2012. Oxidative stress-related PMK-1 P38 MAPK activation as a mechanism for toxicity of silver nanoparticles to reproduction in the nematode Caenorhabditis elegans. Environ Toxicol Chem 31, 585-592.

Liu, J., Pennell, K.G., Hurt, R.H., 2011. Kinetics and mechanisms of nanosilver oxysulfidation. Environ Sci Technol 45, 7345-7353.

Lombi, E., Donner, E., Taheri, S., Tavakkoli, E., Jamting, A.K., McClure, S., Naidu, R., Miller, B.W., Scheckel, K.G., Vasilev, K., 2013. Transformation of four silver/silver chloride nanoparticles during anaerobic treatment of wastewater and post-processing of sewage sludge. Environ Pollut 176, 193-197.

Lowry, G.V., Espinasse, B.P., Badireddy, A.R., Richardson, C.J., Reinsch, B.C., Bryant, L.D., Bone, A.J., Deonarine, A., Chae, S., Therezien, M., Colman, B.P., Hsu-Kim, H., Bernhardt, E.S., Matson, C.W., Wiesner, M.R., 2012. Long-term transformation and fate of manufactured ag nanoparticles in a simulated large scale freshwater emergent wetland. Environ Sci Technol 46, 7027-7036.

Ma, H., Bertsch, P.M., Glenn, T.C., Kabengi, N.J., Williams, P.L., 2009. Toxicity of manufactured zinc oxide nanoparticles in the nematode Caenorhabditis elegans. Environ Toxicol Chem 28, 1324-1330.

Ma, R., Levard, C., Judy, J.D., Unrine, J.M., Durenkamp, M., Martin, B., Jefferson, B., Lowry, G.V., 2014. Fate of zinc oxide and silver nanoparticles in a pilot wastewater treatment plant and in processed biosolids. Environ Sci Technol 48, 104-112.

Ma, R., Levard, C., Marinakos, S.M., Cheng, Y., Liu, J., Michel, F.M., Brown, G.E., Lowry, G.V., 2012. Size-controlled dissolution of organic-coated silver nanoparticles. Environ Sci Technol 46, 752-759.

Marimuthu, S., Rahuman, A.A., Rajakumar, G., Santhoshkumar, T., Kirthi, A.V., Jayaseelan, C., Bagavan, A., Zahir, A.A., Elango, G., Kamaraj, C., 2011. Evaluation of green synthesized silver nanoparticles against parasites. Parasitol Res 108, 1541-1549.

Meyer, J.N., Lord, C.A., Yang, X.Y., Turner, E.A., Badireddy, A.R., Marinakos, S.M., Chilkoti, A., Wiesner, M.R., Auffan, M., 2010. Intracellular uptake and associated toxicity of silver nanoparticles in Caenorhabditis elegans. Aquat Toxicol 100, 140-150. 
Miao, A.J., Schwehr, K.A., Xu, C., Zhang, S.J., Luo, Z., Quigg, A., Santschi, P.H., 2009. The algal toxicity of silver engineered nanoparticles and detoxification by exopolymeric substances. Environ Pollut 157, 3034-3041. Reidy, B., Haase, A., Luch, A., Dawson, K.A., Lynch, I., 2013. Mechanisms of silver nanoparticle release, transformation and toxicity: A critical review of current knowledge and recommendations for future studies and applications. Materials 6, 2295-2350. Reinsch, B.C., Levard, C., Li, Z., Ma, R., Wise, A., Gregory, K.B., Brown, G.E., Jr., Lowry, G.V., 2012. Sulfidation of silver nanoparticles decreases Escherichia coli growth inhibition. Environ Sci Technol 46, 6992-7000.

Roh, J.Y., Park, Y.K., Park, K., Choi, J., 2010. Ecotoxicological investigation of $\mathrm{CeO}_{2}$ and $\mathrm{TiO}_{2}$ nanoparticles on the soil nematode Caenorhabditis elegans using gene expression, growth, fertility, and survival as endpoints. Environ Toxicol Pharmacol 29, 167-172.

Roh, J.Y., Sim, S.J., Yi, J., Park, K., Chung, K.H., Ryu, D.Y., Choi, J., 2009. Ecotoxicity of silver nanoparticles on the soil nematode Caenorhabditis elegans using functional ecotoxicogenomics. Environ Sci Technol 43, 3933-3940.

Santhoshkumar, T., Rahuman, A.A., Rajakumar, G., Marimuthu, S., Bagavan, A., Jayaseelan, C., Zahir, A.A., Elango, G., Kamaraj, C., 2011. Synthesis of silver nanoparticles using Nelumbo nucifera leaf extract and its larvicidal activity against malaria and filariasis vectors. Parasitol Res 108, 693-702.

Schlich, K., Klawonn, T., Terytze, K., Hund-Rinke, K., 2013a. Effects of silver nanoparticles and silver nitrate in the earthworm reproduction test. Environ Toxicol Chem 32, 181-188. Schlich, K., Klawonn, T., Terytze, K., Hund-Rinke, K., 2013b. Hazard assessment of a silver nanoparticle in soil applied via sewage sludge. Env. Sci. Eur. 25, 17.

Shoults-Wilson, W.A., Reinsch, B.C., Tsyusko, O.V., Bertsch, P.M., Lowry, G.V., Unrine, J.M., 2011a. Effect of silver nanoparticle surface coating on bioaccumulation and reproductive toxicity in earthworms (Eisenia fetida). Nanotoxicology 5, 432-444.

Shoults-Wilson, W.A., Zhurbich, O.I., McNear, D.H., Tsyusko, O.V., Bertsch, P.M., Unrine, J.M., 2011b. Evidence for avoidance of Ag nanoparticles by earthworms (Eisenia fetida). Ecotox 20, 385-396.

Tsyusko, O.V., Hardas, S.S., Shoults-Wilson, W.A., Starnes, C.P., Joice, G., Butterfield, D.A., Unrine, J.M., 2012a. Short-term molecular-level effects of silver nanoparticle exposure on the earthworm, Eisenia fetida. Environ Pollut 171, 249-255.

Tsyusko, O.V., Unrine, J.M., Spurgeon, D., Blalock, E., Starnes, D., Tseng, M., Joice, G., Bertsch, P.M., 2012b. Toxicogenomic responses of the model organism Caenorhabditis elegans to gold nanoparticles. Environ Sci Technol 46, 4115-4124.

Tyne, W., Lofts, S., Spurgeon, D.J., Jurkschat, K., Svendsen, C., 2013. A new medium for Caenorhabditis elegans toxicology and nanotoxicology studies designed to better reflect natural soil solution conditions. Environ Toxicol Chem 32, 1711-1717.

Whitley, A.R., Levard, C., Oostveen, E., Bertsch, P.M., Matocha, C.J., von der Kammer, F., Unrine, J.M., 2013. Behavior of Ag nanoparticles in soil: effects of particle surface coating, aging and sewage sludge amendment. Environ Pollut 182, 141-149.

Wiesner, M.R., Lowry, G.V., Jones, K.L., Hochella, M.F., Jr., Di Giulio, R.T., Casman, E., Bernhardt, E.S., 2009. Decreasing uncertainties in assessing environmental exposure, risk, and ecological implications of nanomaterials. Environ Sci Technol 43, 6458-6462. Williams, P.L., Dusenbery, D.B., 1988. Using the nematode Caenorhabditis elegans to predict mammalian acute lethality to metallic salts. Toxicol. Ind. Health 4, 469-478. 
542 Williams, P.L., Dusenbery, D.B., 1990. Aquatic toxicity testing using the nematode, 543 Caenorhabditis elegans. Environ Toxicol Chem 9, 1285-1290.

544 Xiu, Z.M., Zhang, Q.B., Puppala, H.L., Colvin, V.L., Alvarez, P.J., 2012. Negligible particle545 specific antibacterial activity of silver nanoparticles. Nano Lett 12, 4271-4275.

546 Yang, X., Gondikas, A.P., Marinakos, S.M., Auffan, M., Liu, J., Hsu-Kim, H., Meyer, J.N., 547 2012. Mechanism of silver nanoparticle toxicity is dependent on dissolved silver and surface 548 coating in Caenorhabditis elegans. Environ Sci Technol 46, 1119-1127.

549 Yang, X., Jiang, C., Hsu-Kim, H., Badireddy, A.R., Dykstra, M., Wiesner, M., Hinton, D.E., 550 Meyer, J.N., 2014. Silver nanoparticle behavior, uptake, and toxicity in Caenorhabditis elegans: 551 effects of natural organic matter. Environ Sci Technol 48, 3486-3495.

552 Yin, L., Cheng, Y., Espinasse, B., Colman, B.P., Auffan, M., Wiesner, M., Rose, J., Liu, J., 553 Bernhardt, E.S., 2011. More than the ions: the effects of silver nanoparticles on Lolium 554 multiflorum. Environ Sci Technol 45, 2360-2367.

555 Zhang, H., He, X., Zhang, Z., Zhang, P., Li, Y., Ma, Y., Kuang, Y., Zhao, Y., Chai, Z., 2011 a. 556 Nano-CeO2 exhibits adverse effects at environmental relevant concentrations. Environ Sci 557 Technol 45, 3725-3730.

558 Zhang, W., Yao, Y., Sullivan, N., Chen, Y., 2011b. Modeling the primary size effects of citrate559 coated silver nanoparticles on their ion release kinetics. Environ Sci Technol 45, 4422-4428. 